\title{
Extruded contents of colloid cysts after endoscopic removal
}

\author{
Assem M. Abdel Latif, MD, MSc, ${ }^{1,2}$ and Mark M. Souweidane, MD ${ }^{2,3}$ \\ 'Department of Neurological Surgery, Ain Shams University, Cairo, Egypt; ${ }^{2}$ Department of Neurological Surgery, \\ NewYork-Presbyterian Hospital, Weill Medical College, Cornell University, New York; and 'Department of Neurosurgery, \\ Memorial Sloan Kettering Cancer Center, New York, New York
}

OBJECTIVE Mineralized or desiccated colloid cysts pose some unique challenges to endoscopic removal. The extrusion of the solid matrix into the intraventricular compartment has not been previously reported and, as such, no guidance exists regarding its predilection, prevention, and fate.

METHODS Postoperative imaging studies in a registry of patients undergoing endoscopic removal of colloid cyst were reviewed to detect any solid matrix within the ventricular compartment. Preoperative images and operative notes were used to determine if any features were predictive. Serial postoperative images and clinical notes were used to characterize the implications of these findings.

RESULTS From a review of 94 patients, 10 (10.6\%) patients had evidence of an extruded intraventricular solid fragment (median follow-up 4 months; range $0.5-115$ months). Of the evaluable patients, 7 of 9 patients had T1-weighted hyperintense and T2-weighted hypointense cysts on preoperative scans. Seventy-eight percent of the extrusions were on the same side as the endoscopic entry. Three patients demonstrated early fragment migration, but not after 8 months of radiological follow-up. All evaluable patients demonstrated improvement in their hydrocephalus, and none suffered a complication attributable to the intraventricular extruded fragments.

CONCLUSIONS Intraventricular extruded colloid fragments can occur after endoscopic resection, with the possible risk demonstrated as cyst hypointensity on preoperative T2-weighted images. The finding does not seem to result in any clinical morbidity, and radiographic involution is the rule. Migratory capacity, however, does exist and justifies a more frequent imaging surveillance schedule and consideration for removal.

http://thejns.org/doi/abs/10.3171/2015.6.JNS142676

KEY WORDS intraventricular endoscopy; colloid cyst; extruded fragment; mineralization; oncology

$\mathrm{T}$ HIRD ventricular colloid cysts are relatively rare tumors and reportedly represent $0.5 \%$ to $1 \%$ of brain tumors $3,6,10,21,28$ and about $15 \%$ to $20 \%$ of intraventricular tumors. ${ }^{15,25}$ Since the advent of endoscopic removal, their management has been controversial, ${ }^{4,8}$ as emphasized by several clinical series comparing microsurgical and endoscopic approaches. ${ }^{13,17,19}$ There is now ample evidence that an endoscopic approach is a very good alternative to microsurgery $1,8,20,34$ and may in fact be the preferred treatment choice for third ventricular colloid cysts., ${ }^{9,12,27,30}$ As the technique of endoscopic surgical removal matures, so should the comprehensive understanding of the perioperative features that are unique to this approach. It has been our observation that solid intraventricular debris exists on postoperative surveillance imaging that may emanate from the surgical procedure. Currently, there is no prior report of this finding and hence no guidance regarding the fate or avoidance associated with the extrusion of mineralized colloid cyst material into the ventricular system. We set out to determine the incidence of the recognized extrusion of colloid cyst material following endoscopic resection and any implications associated with that event.

\section{Methods}

A prospective registry of all patients treated for colloid cyst has been maintained since 1995 by the senior author (M.M.S.) at a single institution. From that database, pa-

ABBREVIATIONS FOHR = frontal occipital horn ratio.

SUBMITTED November 22, 2014. ACCEPTED June 30, 2015.

INCLUDE WHEN CITING Published online January 8, 2016; DOI: 10.3171/2015.6.JNS142676. 
tients were identified who underwent endoscopic removal. The clinical notes, operative records, and radiological studies were reviewed for each patient. The customary practice was to perform an MRI on the day of surgery for surgical planning, within 48 hours after surgery, at 3 months postoperatively, and then annually.

An extruded fragment was defined as an intraventricular focal area of material on postoperative imaging. The typical imaging characteristics include gravity dependency, CT hyperdensity, T1-weighted hyperintensity, T2weighted hypointensity, and findings on gradient recalled echo and susceptibility-weighted imaging. Discrimination between the extruded material and intraventricular hemorrhage was straightforward based on the signal characteristics and focal/singular nodular morphology, as opposed to the material that exhibited bilateral conformity with the ventricular surface.

Eligible patients then had their MRI scans reviewed to determine the location of the fragment, the maximum diameter, temporal changes, signal characteristics, and degree of ventriculomegaly. Ventricular size evaluation was done using the frontal occipital horn ratio (FOHR). ${ }^{24}$ The degree of resolution of the symptoms and long-term control rates were also assessed.

\section{Results}

Evidence of extruded colloid material was detected in 10 of 94 patients $(10.6 \%)$. The male/female ratio was $1: 1$, the mean age at surgery was 51.5 years (range 18-67 years), and the median age was 57.5 years. One patient ( $\mathrm{Pa}-$ tient 5) was lost to follow-up and was excluded from the analysis. For the remaining 9 patients, the mean followup was 37 months (range 0.5-115 months) with a median of 26 months. The number of follow-up scans per patient ranged from 1 to 10 (median 4 scans/patient). All patients were administered perioperative intravenous corticosteroids. Preoperative clinical and imaging characteristics were reviewed in an attempt to identify a predisposition for extruded fragments (Table 1). Preoperative MRI scans were available for review in 9 of 10 patients. The maximal and mean preoperative diameters of the colloid cysts were $16.9 \mathrm{~mm}$ and $13 \mathrm{~mm}$ (range $9.18-16.9 \mathrm{~mm}$ ). The T1weighted imaging characteristics included hyperintensity in 7 patients, hypointensity in 0 patients, and isointensity in 2 patients. The T2-weighted imaging behavior demonstrated hyperintensity in 0 patients, hypointensity in 7 patients, and isointensity in 2 patients, and 8 of 9 patients (88.9\%) demonstrated T2-weighted focal signal drop-out that was indicative of a more solid matrix (Fig. 1). Seven of $9(77.8 \%)$ patients had hydrocephalus (FOHR $>0.37$ ) preoperatively.

Intraoperative suspicion of extruded fragments was reported in all patients with available operative details ( 8 of 10 patients), and postoperative imaging provided radiological confirmation. The imaging features of the extruded fragments were reviewed (Table 2). All extruded fragments were hypointense on postoperative T2-weighted imaging. The maximal diameter of the fragments on the initial postoperative imaging ranged from 4.2 to $14.0 \mathrm{~mm}$ (mean $8.3 \mathrm{~mm}$ ). Longitudinal scans were available for 8 patients. Of these, 7 patients showed a progressive decrease in the maximal diameter. Complete disappearance occurred in 4 patients over a mean duration of 21.5 months. On the initial postoperative imaging, 7 of $9(77.8 \%)$ fragments were positioned on the ipsilateral side to the surgical entry site. Of interest, 3 fragments demonstrated eventual migration within the ventricular compartment, and 2 of these fragments did cross the midline (Fig. 2). Given this observation, an attempt was unsuccessfully made on one occasion to provoke movement, and dynamic CT scanning was used to further assess the potential for migration (Fig. 3). There was never any movement detected beyond 8 months of radiological follow-up that was suggestive of the eventual incorporation into the ependymal surface (Fig. 4).

Of the 9 patients with an established follow-up, 7 patients were suitable for radiographic evaluation of ventricular size (FOHR). All of the evaluable patients showed improvement in the degree of ventricular enlargement, with a mean reduction of 0.04357 (95\% CI $0.01785-0.06930 ; \mathrm{p}=$

TABLE 1. Basic patient characteristics

\begin{tabular}{|c|c|c|c|c|c|}
\hline $\begin{array}{c}\text { Patient } \\
\text { No.* }\end{array}$ & Age (yrs) & Sex & Symptoms & $\begin{array}{l}\text { Cyst Size } \\
\text { (mm) }\end{array}$ & Preop Hydrocephalus (FOHR) $†$ \\
\hline 1 & 61 & $\mathrm{~F}$ & Headache, loss of consciousness, visual, gait & 13 & Yes $(0.43)$ \\
\hline 2 & 57 & M & Headache, vomiting, memory lapses & 12 & Yes $(0.45)$ \\
\hline 3 & 44 & $\mathrm{~F}$ & Headache, fogginess & 11.8 & Yes $(0.45)$ \\
\hline 4 & 65 & $\mathrm{~F}$ & Headache, ataxia, collapse & 16.9 & Yes $(0.52)$ \\
\hline 5 & 33 & M & Headaches & 11.46 & Yes $(0.53)$ \\
\hline 6 & 18 & $\mathrm{~F}$ & Headaches & 9.18 & No $(0.376)$ \\
\hline 7 & 67 & M & Syncopal episode & 16.73 & Yes $(0.55)$ \\
\hline 8 & 63 & M & Syncopal episode & NA & NA \\
\hline 9 & 58 & $\mathrm{M}$ & Dizziness \& vertigo & 10 & Yes $(0.50)$ \\
\hline 10 & 49 & $F$ & Accidental diagnosis & 16.28 & No $(0.318)$ \\
\hline
\end{tabular}



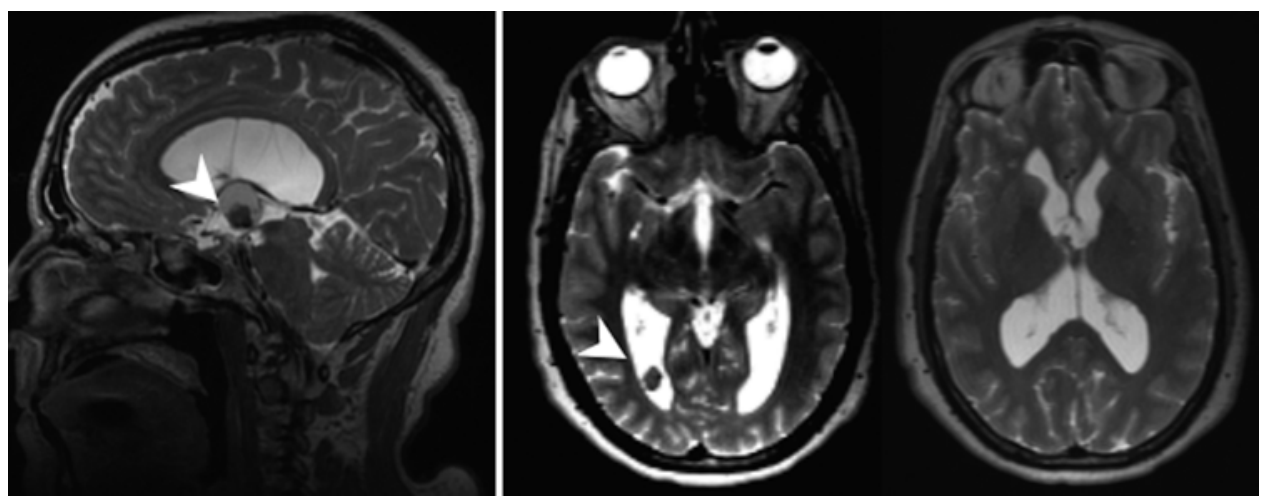

FIG. 1. Patient 9. Left: Sagittal T2-weighted MR image showing a large anterior third ventricular colloid cyst with hyperintense signaling and a focal area with T2-weighted signal drop-out (arrowhead), indicating more solid or mineralized contents that are prone to extrusion with endoscopic extirpation. Right: Postoperative axial T2-weighted MR image showing an extruded hypointense fragment in the right occipital horn (arrowhead), with another axial cut showing that the frontal horns were clean at that time.

0.006, paired Student t-test) in FOHR (-9.2\%) at the latest follow-up (mean 35.9 months). It is noteworthy that none of these patients required a CSF diversion procedure during the follow-up period. No patient demonstrated clinical findings indicative of aseptic meningitis (e.g., constellation of fevers, nuchal rigidity, or sterile CSF pleocytosis).

\section{Discussion}

Purely endoscopic removal has been shown to positively impact the operative management and outcome of patients with third ventricular colloid cysts. Because this approach has only recently evolved relative to microsurgical removal, it is expected that the unique technical features and operative strategies will become further detailed. Over the past 2 decades, the senior author (M.M.S.) has observed infrequent extruded fragments of solid cysts when performing purely endoscopic colloid cyst removal. This report attempts to provide some clarity concerning the predictive features and management strategies in situ- ations when solid colloid cyst material becomes dislodged into the ventricular system.

Due to the small caliber of endoscopic working chambers, limited options exist for the evacuation of colloid cysts. In the majority of cases, simple aspiration through various suction cannulas (1-2 mm) will suffice. Rarely, the cyst content is dense or viscous enough that it precludes a thorough evacuation using small-caliber aspirators prior to cyst wall removal. In these circumstances we have recently integrated a tissue-shaving device (NICO Myriad, NICO Corp.) for the piecemeal removal of colloid cysts. The dense core of material that remains after suction aspiration is amenable to tissue shaving since it is avascular nonviable tissue. An alternative method of removal is to extract the colloid cyst wall simultaneously with these more solid cyst contents. En bloc removal is only accomplished by extracting the cyst through the intracerebral endoscopic path since the main working portals on contemporary endoscopes are far smaller than the typical cyst size. When en bloc removal is performed, the contents of

\section{TABLE 2. Extruded fragment characteristics}

\begin{tabular}{|c|c|c|c|c|c|c|}
\hline $\begin{array}{l}\text { Patient } \\
\text { No.* }\end{array}$ & $\begin{array}{l}\text { Follow-Up } \\
\text { (mos) }\end{array}$ & $\begin{array}{l}\text { Fragment Size } \\
\qquad(\mathrm{mm}) \dagger\end{array}$ & Fragment Location & $\begin{array}{l}\text { T2-Weighted } \\
\text { Fragment }\end{array}$ & $\begin{array}{l}\text { FOHR on Last } \\
\text { Scan }\end{array}$ & $\begin{array}{c}\text { Change in FOHR on } \\
\text { Follow-Up } \neq\end{array}$ \\
\hline 1 & 16 & $4.16 \rightarrow \mathrm{CR}$ & Lt occipital-It frontal & Hypo & 0.379 & $-0.051(12 \%)$ \\
\hline 2 & 26 & $8.5 \rightarrow 1.69$ & Rt occipital_It frontal & Hypo & 0.42 & $-0.03(6.7 \%)$ \\
\hline 3 & 43 & $7.6 \rightarrow \mathrm{CR}$ & Lt occipital & Hypo & 0.4 & $-0.05(11.1 \%)$ \\
\hline 4 & 44 & $14.04 \rightarrow \mathrm{CR}$ & Lt occipital & Hypo & 0.43 & $-0.09(17.3 \%)$ \\
\hline 5 & NA & 9 & Rt occipital & Нypo & NA & NA \\
\hline 6 & 84 & NA & NA & NA & NA & NA \\
\hline 7 & 115 & $7.97 \rightarrow 3.4$ & Rt occipital & Hypo & 0.529 & $-0.021(3.8 \%)$ \\
\hline 8 & 0.5 & 9.17 & Rt occipital & Hypo & NA & NA \\
\hline 9 & 4 & $10 \rightarrow 8.2$ & Rt occipital—rt frontal—It occipital & Нypo & 0.442 & $-0.058(11.6 \%)$ \\
\hline 10 & 3 & $4.43 \rightarrow \mathrm{CR}$ & Rt atrial & Hypo & 0.313 & $-0.005(1.6 \%)$ \\
\hline
\end{tabular}

$\mathrm{CR}=$ complete resolution; Hypo = hypointense.

* Patient 5 was lost to follow-up; Patient 6 only had postoperative imaging reports available, which do not mention the intraventricular fragments and FOHR was not calculated; and Patient 8 did not have preoperative imaging in the database for comparison, only received postoperative MRI, and follow-up MRI was not available for comparison of the FOHR values.

$\dagger$ Sizes at diagnosis and the last follow-up scan are shown on the left and right sides of the arrow, respectively.

$\ddagger$ The mean reduction in FOHR on follow-up was $0.0436(p=0.006)$. 

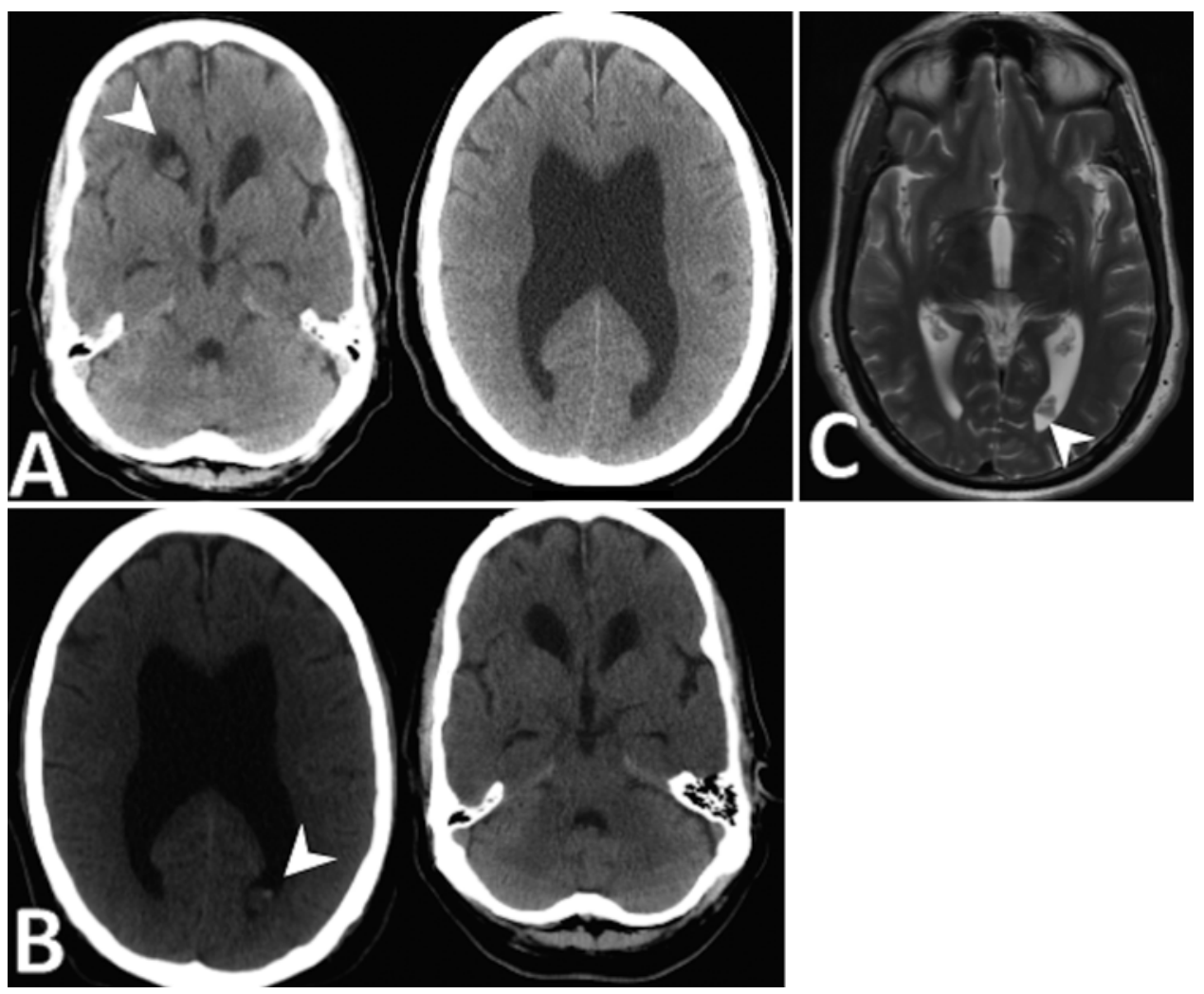

FIG. 2. Patient 9. Postoperative scans obtained as follow-up of the extruded colloid fragment. A: CT scans obtained 12 days postoperatively showing that the fragment has moved from the right occipital horn to the right frontal horn (arrowhead). Note in the slice on the right that both occipital horns are devoid of fragments. B: CT scans obtained 4 weeks postoperatively, showing the fragment has moved to the left occipital horn (arrowhead) with clean frontal horns at the same time in the slice on the right. C: MR image obtained 4 months postoperatively, showing that the fragment was still in the left occipital horn (arrowhead).

the cyst can get expelled out of the lesion as it is constricted into the white matter tract. Intuitively, the extrusion of solid cyst material is more likely to occur with very dense or mineralized content; this material was referred to nearly 100 years ago by Walter Dandy as "queer concretions."' Predicting which patients are at risk for the extrusion of these solid components would be helpful during surgical planning, postoperative follow-up, and patient counseling. In our experience, the cysts with the greatest density were predictable based on signal drop-out on T2-weighted MRI. The finding that 9 of 10 patients (90\%) with extruded fragments had T2-weighted signal drop-out on their preoperative MRI versus 39 of 74 patients (53\%) without intraoperative extrusion supports this notion $(\mathrm{p}=0.0383$;
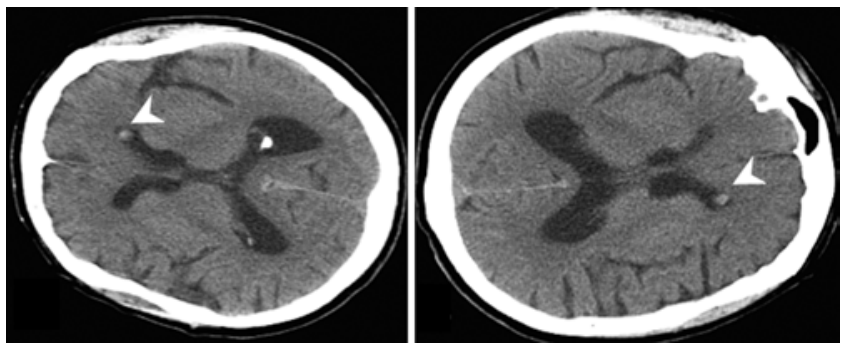

FIG. 3. Patient 2. Eight-month postoperative dynamic CT scan of the right lateral (left) and left lateral (right) decubitus positions used to evaluate the movement of the fragment seen in the left frontal horn (arrowhead).
Fisher exact test). Cyst density has been previously correlated with imaging. ${ }^{2,18,31}$ Therefore, when a T2-weighted hypointense core is seen on preoperative imaging, simple endoscopic aspiration is expected to be difficult,,$^{12}$ and the operative plan now incorporates a tissue-shaving device. Recent reports of using a "renal stone basket" in similar endoscopic intraventricular procedures might also be considered in this circumstance. ${ }^{5,29}$ Upon comparison with the control group (mean age 39.5 years) without intraoperative extrusion, older patient age at the time of surgery was the only clinical variable associated with a higher likelihood of intraoperative extrusion (mean age 51.5 years) ( $\mathrm{p}$ $=0.022$; mean difference 12 years; 95\% CI 1.8-22.3; Student t-test). Another variable is preoperative hydrocephalus, and the group with intraoperative extrusion (mean FOHR 0.458) had remarkably more hydrocephalus than the group without intraoperative extrusion (mean FOHR 0.414; $p=0.054$; unpaired Student t-test).

The implications of extruded solid fragments are unknown and have not been previously reported. Hypothetically, a number of concerns arise: obstructive hydrocephalus (from a fragment blocking a CSF pathway), chemical meningitis, and heterotopic cyst recurrence. ${ }^{33}$ Ipsilateral intraventricular deposition occurred in 7 of 9 patients, confirming the logical expectation. The finding of intraventricular migration in 3 patients was concerning, with 2 patients demonstrating contralateral movement. All of these fragments demonstrated eventual adherence to the 

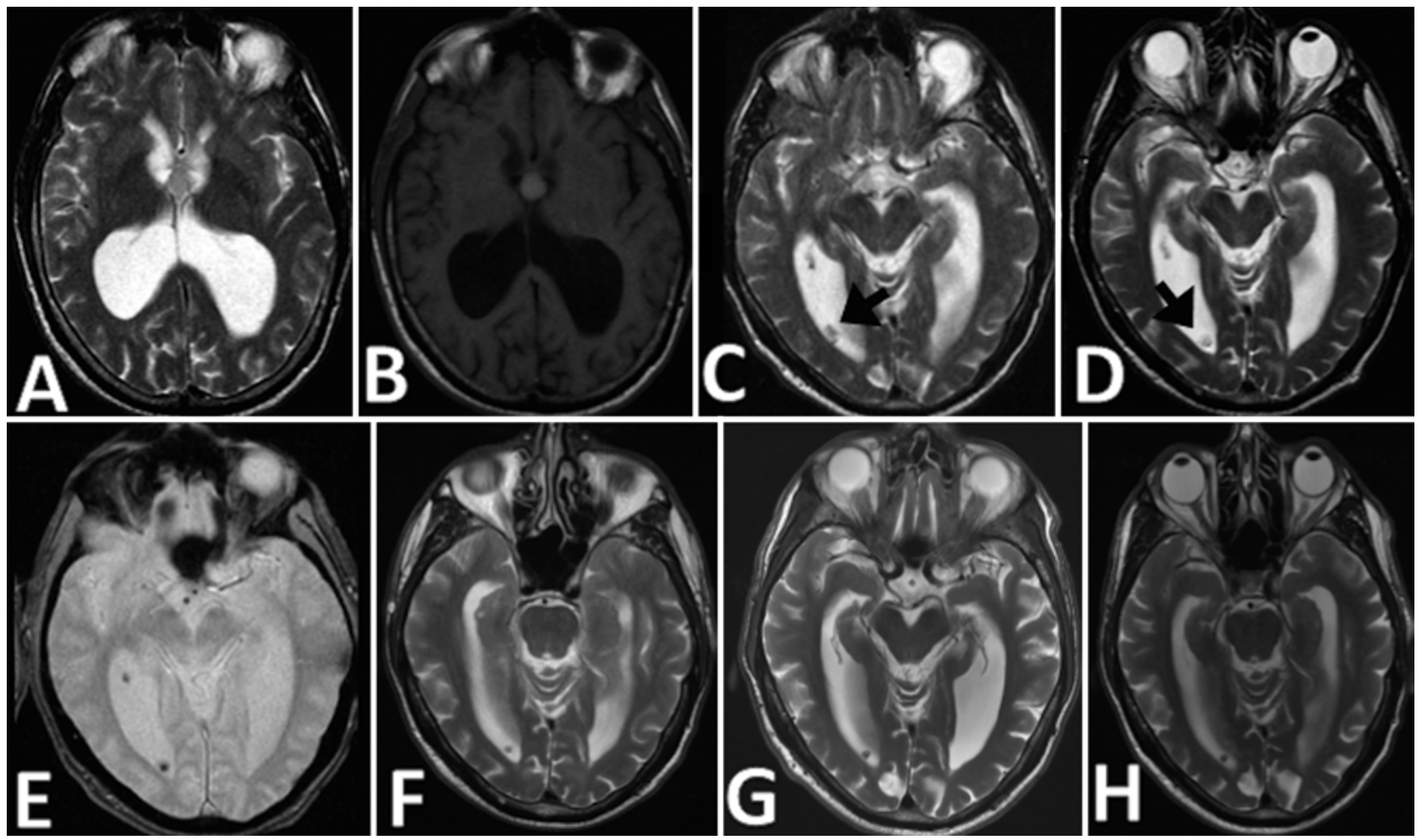

FIG. 4. Patient 7. This patient had the longest follow-up period. Preoperative T2-weighted (A) and T1-weighted (B) MR images showing the isointense and hyperintense signals of the colloid cyst. C and D: T2-weighted MR image (C) obtained 7 days postoperatively, showing an extruded fragment in the right occipital horn (arrow), which retained its general position, size, and signal characteristics at 2 months postoperatively (D). E: Gradient-echo T2*-weighted MR image obtained 24 months postoperatively, showing the susceptibility of the fragment in same position. F-H: T2-weighted MR images obtained at 48 months (F), 84 months $(\mathrm{G})$, and 120 months postoperatively $(\mathrm{H})$ showing the same fragment position.

ependymal surface over a mean of 8.3 months. This recognition of mobility does highlight the potential risk of acute noncommunicating hydrocephalus. Given this finding, endoscopic retrieval is a legitimate management option, although it was not performed in this series. This rare phenomenon also justifies frequent postoperative surveillance.

While cyst remnants have been shown to predispose patients to colloid cyst recurrence, expelled matrix material did not result in a known recurrence over a mean follow-up of 42 months. ${ }^{1,14,16,34}$ Similarly, no clinical recognition of aseptic meningitis or postinflammatory communicating hydrocephalus has been seen in these patients. These clinical sequelae have been previously attributed to the colloid material admixing within the CSF.1,14,22,26,32 In 2002, Motoyama et al. reported a case of spontaneous rupture of a presumed colloid cyst that occurred without surgical intervention and the eventual development of hydrocephalus 6 months later. They attributed this to a possible inflammatory reaction or change in the CSF absorption by the extruded cyst contents. ${ }^{23}$ Whether the lack of these finding in our series is related to our routine use of perioperative intravenous corticosteroids remains uncertain.

\section{Conclusions}

Intraventricular extruded colloid fragments can occur after endoscopic resection. Preoperative, T2-weighted hy- pointense cyst content indicates a predisposition toward extrudation, and appropriate surgical planning should be instituted. The finding of an extruded fragment does not seem to result in any clinical morbidity, and radiographic involution is typical. Rarely, however, migration has been recognized and close MR surveillance or endoscopic retrieval should be considered.

\section{References}

1. Abdou MS, Cohen AR: Endoscopic treatment of colloid cysts of the third ventricle. Technical note and review of the literature. J Neurosurg 89:1062-1068, 1998

2. Atlas S (ed): Magnetic Resonance Imaging of the Brain and Spine. Philadelphia: Lippincott Raven, 1996

3. Beems T, Menovsky T, Lammens M: Hemorrhagic colloid cyst: case report and review of the literature. Surg Neurol 65:84-86, 2006

4. Boogaarts HD, Decq P, Grotenhuis JA, Le Guérinel C, Nseir $\mathrm{R}$, Jarraya B, et al: Long-term results of the neuroendoscopic management of colloid cysts of the third ventricle: a series of 90 cases. Neurosurgery 68:179-187, 2011

5. Carr K, Zuckerman SL, Tomycz L, Pearson MM: Endoscopic removal of an intraventricular primitive neuroectodermal tumor: retrieval of a free-floating fragment using a urological basket retriever. J Neurosurg Pediatr 12:25-29, 2013

6. Carrasco R, Pascual JM, Medina-López D, BurdaspalMoratilla A: Acute hemorrhage in a colloid cyst of the third ventricle: A rare cause of sudden deterioration. Surg Neurol Int 3:24, 2012

7. Dandy WE: Benign Tumors in the Third Ventricle of the 
Brain: Diagnosis and Treatment. Springfield, IL: Charles C Thomas, 1933

8. Decq P: Endoscopy or microsurgery: is the never-ending debate concerning the choice of surgical strategy for colloid cysts of the third ventricle still a topical issue or has it been resolved? World Neurosurg 80:498-499, 2012

9. Delitala A, Brunori A, Russo N: Supraorbital endoscopic approach to colloid cysts. Neurosurgery 69 (2 Suppl Operative):ons176-183, 2011

10. Desai KI, Nadkarni TD, Muzumdar DP, Goel AH: Surgical management of colloid cyst of the third ventricle-a study of 105 cases. Surg Neurol 57:295-304, 2002

11. El Khoury C, Brugières P, Decq P, Cosson-Stanescu R: Colloid cysts of the third ventricle: are MR imaging patterns predictive of difficulty with percutaneous treatment? AJNR Am J Neuroradiol 21:489-492, 2000

12. Greenlee JDW, Charles T, Ghahreman A, Kwok B: Purely endoscopic resection of colloid cysts. Neurosurgery 62 (3 Suppl 1):ONS51-ONS56, 2008

13. Grondin RT, Hader W, MacRae ME, Hamilton MG: Endoscopic versus microsurgical resection of third ventricle colloid cysts. Can J Neurol Sci 34:197-207, 2007

14. Hellwig D, Bauer BL, Schulte M, Gatscher S, Riegel T, Bertalanffy H: Neuroendoscopic treatment for colloid cysts of the third ventricle: the experience of a decade. Neurosurgery 52:525-533, 2003

15. Hernesniemi J, Romani R, Dashti R, Albayrak BS, Savolainen S, Ramsey C III, et al: Microsurgical treatment of third ventricular colloid cysts by interhemispheric far lateral transcallosal approach-experience of 134 patients. Surg Neurol 69:447-456, 2008

16. Hoffman CE, Savage NJ, Souweidane MM: The significance of cyst remnants after endoscopic colloid cyst resection: a retrospective clinical case series. Neurosurgery 73:233-239, 2013

17. Horn EM, Feiz-Erfan I, Bristol RE, Lekovic GP, Goslar PW, Smith KA, et al: Treatment options for third ventricular colloid cysts: comparison of open microsurgical versus endoscopic resection. Neurosurgery 60:613-620, 2007

18. Kachhara R, Das K, Nair S, Gupta AK: Changing characteristics of a colloid cyst of the third ventricle. Neuroradiology 41:188-189, 1999

19. Kehler U, Brunori A, Gliemroth J, Nowak G, Delitala A, Chiappetta F, et al: Twenty colloid cysts-comparison of endoscopic and microsurgical management. Minim Invasive Neurosurg 44:121-127, 2001

20. Lewis AI, Crone KR, Taha J, van Loveren HR, Yeh HS, Tew JM Jr: Surgical resection of third ventricle colloid cysts. Preliminary results comparing transcallosal microsurgery with endoscopy. J Neurosurg 81:174-178, 1994

21. Little JR, MacCarty CS: Colloid cysts of the third ventricle. J Neurosurg 40:230-235, 1974

22. Margetis K, Souweidane MM: Endoscopic treatment of intraventricular cystic tumors. World Neurosurg 79 (2 Suppl):S19.e1-S19.e11, 2012

23. Motoyama Y, Hashimoto H, Ishida Y, Iida J: Spontaneous rupture of a presumed colloid cyst of the third ventriclecase report. Neurol Med Chir (Tokyo) 42:228-231, 2002

24. O’Hayon BB, Drake JM, Ossip MG, Tuli S, Clarke M: Fron- tal and occipital horn ratio: A linear estimate of ventricular size for multiple imaging modalities in pediatric hydrocephalus. Pediatr Neurosurg 29:245-249, 1998

25. Ogbodo E, Kaliaperumal C, Bermingham N, O’Sullivan M: Spontaneous haemorrhage and rupture of third ventricular colloid cyst. BMJ Case Rep 2012:2012, 2012

26. Opeskin K, Anderson RM: Colloid cysts of the third ventricle: fatal outcomes associated with unusual presentation Clinical records. J Clin Neurosci 2:307-311, 1995

27. Qiao L, Souweidane MM: Purely endoscopic removal of intraventricular brain tumors: a consensus opinion and update. Minim Invasive Neurosurg 54:149-154, 2011

28. Ryder JW, Kleinschmidt-DeMasters BK, Keller TS: Sudden deterioration and death in patients with benign tumors of the third ventricle area. J Neurosurg 64:216-223, 1986

29. Schirmer CM, Heilman CB: Complete endoscopic removal of colloid cyst using a nitinol basket retriever. Neurosurg Focus 30(4):E8, 2011

30. Schroeder HWS, Gaab MR: Endoscopic resection of colloid cysts. Neurosurgery 51:1441-1445, 2002

31. Scotti G, Scialfa G, Colombo N, Landoni L: MR in the diagnosis of colloid cysts of the third ventricle. AJNR Am J Neuroradiol 8:370-372, 1987

32. Wang Z, Yan H, Wang D, Wang S, Liu R, Zhang Y: A colloid cyst in the fourth ventricle complicated with aseptic meningitis: a case report. Clin Neurol Neurosurg 114:1095-1098, 2012

33. Zabihyan S, Etemadrezaie $\mathrm{H}$, Baharvahdat $\mathrm{H}$, Baradaran A, Ganjeefar B, Bohl MA, et al: Remote transplantation of a third ventricle colloid cyst: case report. J Neurosurg 122:1406-1410, 2015

34. Zohdi A, El Kheshin S: Endoscopic approach to colloid cysts. Minim Invasive Neurosurg 49:263-268, 2006

\section{Disclosures}

Dr. Souweidane is a consultant for Aesculap.

\section{Author Contributions}

Conception and design: Souweidane. Acquisition of data: Abdel Latif. Analysis and interpretation of data: Abdel Latif. Drafting the article: Abdel Latif. Critically revising the article: Souweidane. Reviewed submitted version of manuscript: both authors. Approved the final version of the manuscript on behalf of both authors: Souweidane. Statistical analysis: Abdel Latif.

\section{Supplemental Information \\ Previous Presentations}

Portions of this work were presented as a poster at the 2013 annual meeting of the Congress of Neurological Surgeons in San Francisco, October 19-23, 2013.

\section{Correspondence}

Mark M. Souweidane, Department of Neurological Surgery, NewYork-Presbyterian Hospital, Weill Medical College, Cornell University, 525 E. 68th St., Box 99, New York, NY 10065. email: mmsouwei@med.cornell.edu. 